\title{
"PESCA PROFISSIONAL", MUDANÇA SOCIAL E RESISTÊNCIA EM SANTARÉM, PARÁ.
}

\author{
Fabiano Gontijo ${ }^{1}$ \\ Igor Erick ${ }^{2}$
}

A região amazônica é conhecida pela maneira peculiar como as águas abundantes regem a vida de seus moradores, caracterizando suas relações, por um lado, com o ambiente e os recursos naturais de modo geral, e, por outro, entre os humanos e com os não humanos, e, assim, implementando símbolos, mitos e ritos que organizam e dão sentido a modos de ser, estar e pensar singulares (Pizarro, 2012; Furtado, Leitão \& Melo, 1993). Nesse contexto, não é de surpreender que a atividade pesqueira - e tudo o que a ela está atrelado - se torne fundamental para o entendimento do funcionamento do regime das águas que marcadamente singulariza o sujeito amazônida, aquele chamado, na vasta literatura já clássica sobre o assunto, de "caboclo", "ribeirinho" ou "homem amazônico" (Wagley, 1974; Miller, 1977; Parker, 1985; Motta-Maués, 1989; Harris, 1998; Lima-Ayres, 1999; Rodrigues, 2006).

Registros arqueológicos pré-coloniais e históricos não poderiam deixar de enfatizar, a seu turno, a "vocação aquática" das atividades dos humanos que povoaram e que vêm ocupando, em seus movimentos migratórios diversos, essa vasta região (Fausto, 2000). Neves avança que "as evidências de ocupação humana na foz do Rio Tapajós com o Amazonas [onde hoje se encontra a cidade de Santarém] remontam a cerca de 7 mil anos e a área urbana atual tem sido ocupada continuamente há pouco mais de mil anos, desde o século 10.” (Neves, 2015: 80) Arqueólogos que atuam na região de Santarém avançam ainda que ali existiu talvez aquele que tenha sido o maior aglomerado urbano da Amazônia pré-colonial. Os povos que viveram ali sucederam-se em função de suas atividades relacionadas às águas abundantes, ou seja, à pesca nos rios, igarapés, furos e igapós e à coleta na várzea (Neves, 2006; Schaan, 2010).

No entanto, as grandes transformações econômicas e políticas das últimas duas ou três décadas decorrentes das novas configurações do modo de expansão capitalista global, com suas consequências sociais e culturais e seus rearranjos territoriais na região amazônica parecem acarretar uma série de alterações nos modos de vida dos pescadores locais (Melo, A. F., 1985; Aviz, A., 2006; Castro \& Moura, 2012). Em Santarém,

\footnotetext{
${ }^{1}$ Universidade Federal do Pará, Brasil.

${ }^{2}$ Universidade Federal do Oeste do Pará, Brasil.
} 
pudemos acompanhar, durante dez meses entre 2014 e 2015, a vida de duas famílias de pescadores tradicionais que resistem à nova realidade da pesca industrial. Através de suas experiências cotidianas, foi possível perceber as consequências e os impactos do avançado processo de industrialização em andamento na região sobre a "pesca profissional" - é assim que essas famílias designam o conjunto de atividades das quais tiram seu sustento, a saber, o que tradicionalmente vem sendo chamado, na literatura especializada, de pesca artesanal (Furtado \& Quaresma, 2002). Esses pescadores opõem, assim, a pesca profissional à pesca industrial, esta última incentivada por grupos empresariais ligados a grandes conglomerados alimentícios nacionais e estrangeiros que vêm se apropriando dos territórios tradicionais de pesca localizados no perímetro urbano da cidade.

Trata-se aqui de apresentar imagens representativas de fragmentos de saberes, fazeres, crenças, visões de mundo, ethos e tecnologias que acompanham as memórias dos sujeitos através de um processo dinâmico que envolve marcadores sociais e a maneira como esses conhecimentos conformam uma espécie de identidade de resistência política no contexto urbano de grandes transformações por que passa Santarém.

Na colônia da Vila Arigó, às margens do Rio Tapajós, encontramos as famílias de Raimundo Pereira, conhecido como Seu Cebolão - um homem de 70 anos, esbelto e de voz potente - e de Armando Mendes Morais - um outro homem de 61 anos, altivo e bastante prolixo. Eles nos expuseram seus ricos acervos vivos de saberes e conhecimentos sobre a pesca e, com entusiasmo, colocaram-nos a par da problemática da resistência política (espacial, física, cultural e territorial) diante dos grandes empreendimentos que vêm desafiando a manutenção da "pesca profissional" no contexto urbano santareno.

Das águas, Seu Cebolão e Seu Armando retiram aracus (Schizodon spp.), pirapitingas (Piaractus brachypomus), pacus (Myeleus spp.), curimatãs (Prochilodus nigricans), maparás (Hypophtalmus spp.), fura-calças (Pimelodina flavipinnis), branquinhas (Curimata amazonica) e matrinxãs (Brycon cephalus), jatuaranas (Brycon spp.) e tambaquis (Colossoma macropomum), usando-se de suas embarcações (bajaras), fabricadas por eles mesmos, assim como tarrafas, malhadeiras ${ }^{3}$, bubuias ${ }^{4}$, o espinhel, o caniço e toda uma parafernália que configuram os modos de fazer, pensar e agir na

\footnotetext{
${ }^{3}$ Um tipo de rede de pesca.

${ }^{4}$ Uma malhadeira grande usada para pegar peixes lisos.
} 
pesca desses senhores. Seu Cebolão diz que cada pescador tem as suas especialidades, mas quem é "profissional mesmo" tem que saber lidar com toda essa parafernália - já que aquele que só sabe manusear uma ferramenta é apenas um "aprendiz". Um bom pescador "profissional" é aquele que sabe pescar com todas as ferramentas e, sobretudo, aquele que faz as suas próprias ferramentas, personalizando-as. Seu Cebolão manuseia todas essas ferramentas e faz seus instrumentos, embora tenha "se apaixonado" por um deles em particular: a tarrafa. No começo de sua prosa, ele revigora o modo de tecer a tarrafa e diz "que a agulha tem que estar sempre alinhada e que o pescador tem que estar sempre conectado a ela, assim como um pai aos seus filhos".

Seu Armando, por sua vez, é conhecido pelos seus parceiros de pesca com os epítetos de "o pescador brabo" ou "o corajoso", renomado em toda a região como sendo o único que adentra destemidamente os ramais aquáticos e igapós para pescar em plena época que "os rios estão cheios" (no inverno amazônico, quando as águas das abundantes chuvas incham os volumes dos rios). É nesse momento e nesses lugares que mora o perigo para os pescadores, dentre os quais as citadas anaconda e onça d'água, os maiores "predadores" de todos os pescadores... exceto de Seu Armando! Em suas narrativas, frisa constantemente que já matou ambas as espécies de "predadores" em dias de saída para a pesca. Ressalta que “os predadores moram debaixo d'água, mas a onça d'água, ela não só vive na água, mas como na terra também. Ela é toda preta e tem uma parte branca no pescoço, é tipo um formato de um colar, mas usa um chapeuzinho branco em sua cabeça." A anaconda, a sucuri, é traiçoeira, enquanto que a onça é a grande "predadora". Quando os "predadores" se deparam com o pescador, este se utiliza de astúcias para não ser pego. Esse método astucioso é relatado como sendo de uso para além da pesca, também no convívio social cotidiano (Ingold, 1995; Descola, 1998).

Seu Cebolão é o compromissado e aguerrido líder da colônia de pescadores que compartilha gentilmente sua experiência com os demais pescadores que resistem aos avanços da grande indústria sobre seus territórios de pesca e sobre a área de ancoragem das bajaras. Seu Armando é o destemido e corajoso pescador que ensina aos demais resistentes como lidar com as armadilhas da natureza para fazer imperar o pescador diante dos banzeiros dos Rios Tapajós e Amazonas. Mas, são as balsas cargueiras, o estaleiros navais e as empresas de transporte que parecem ameaçar muito mais do que a natureza esse modo de vida tradicional. 


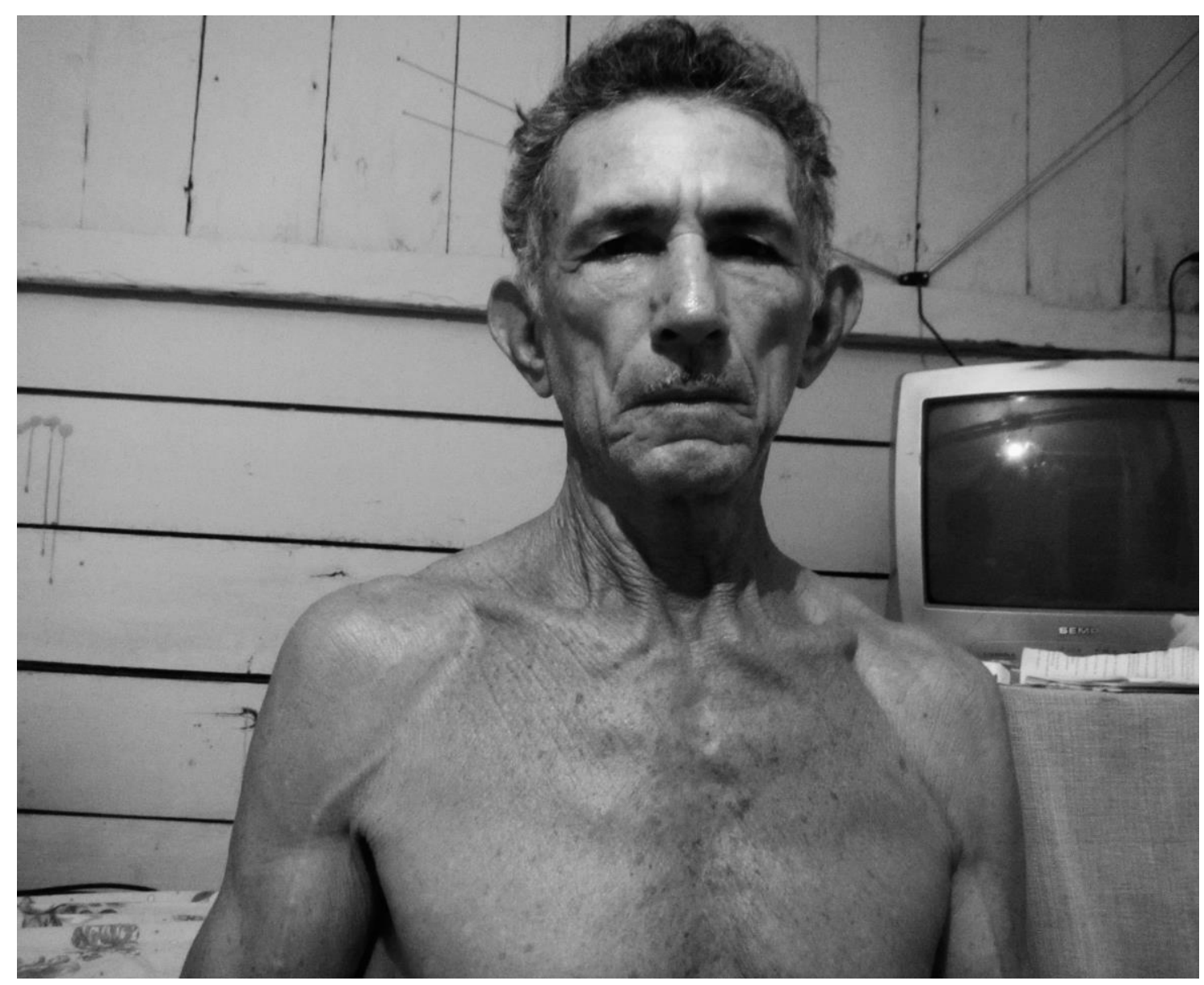

“Tira um retrato meu!” Foto: Igor Erick. 


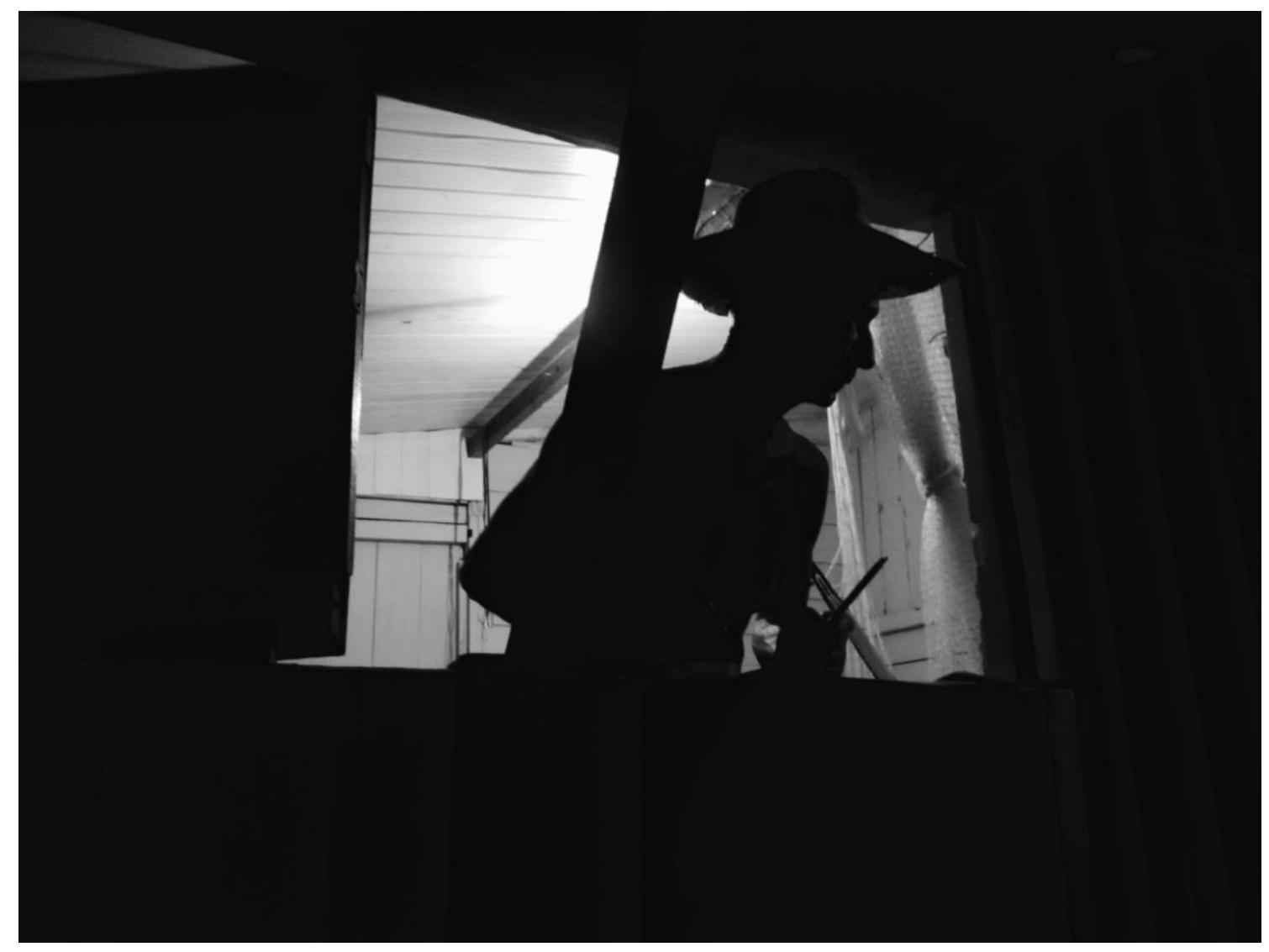

"Quem pegou a minha agulha? Ohhhhh Naiara, cadê a minha agulha?? Foto: Igor Erick. 


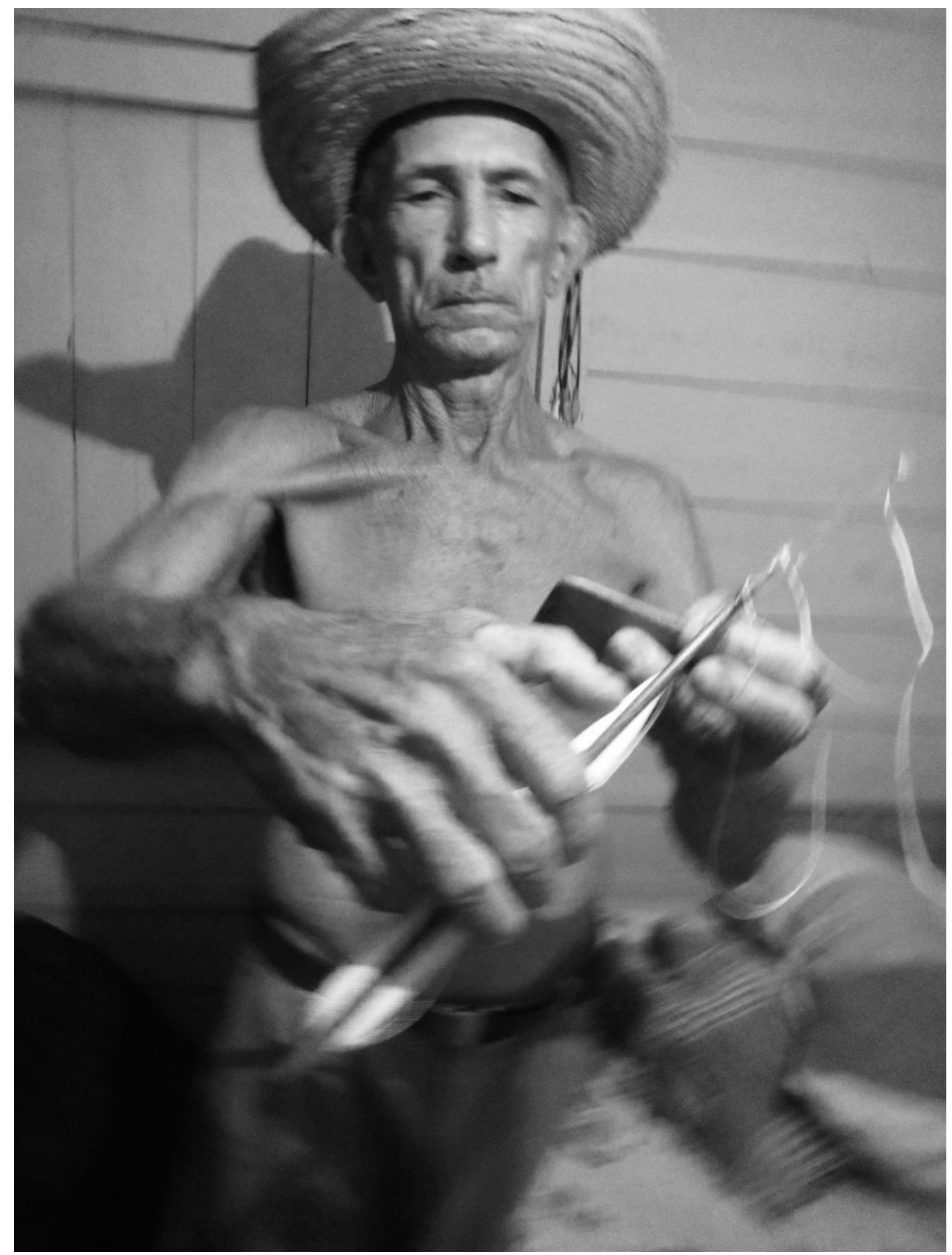

“Presta atenção no movimento da agulha!” Foto: Igor Erick. 


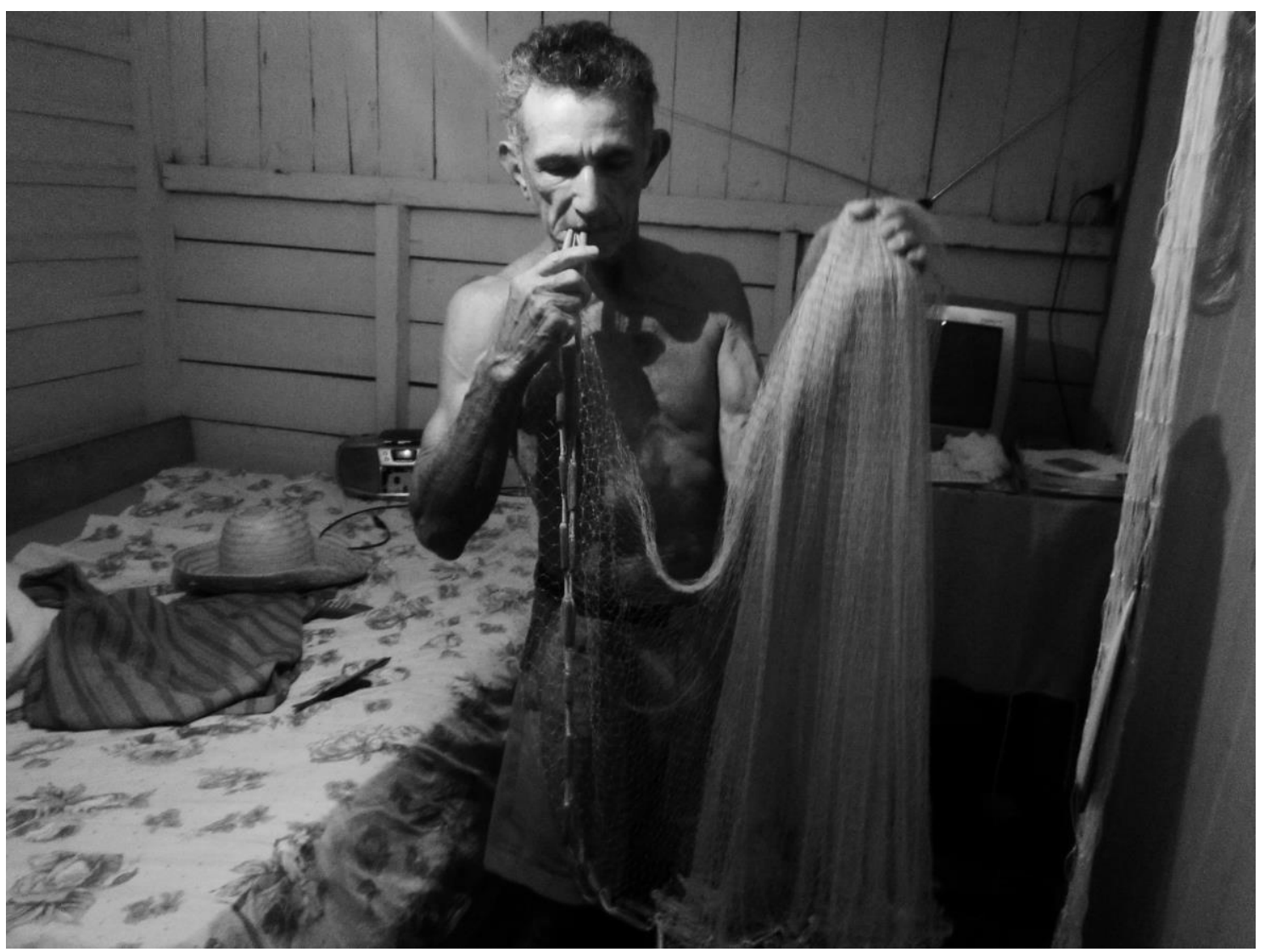

“Essa aqui é a minha paixão, essa é a famosa tarrafa.” Foto: Igor Erick.

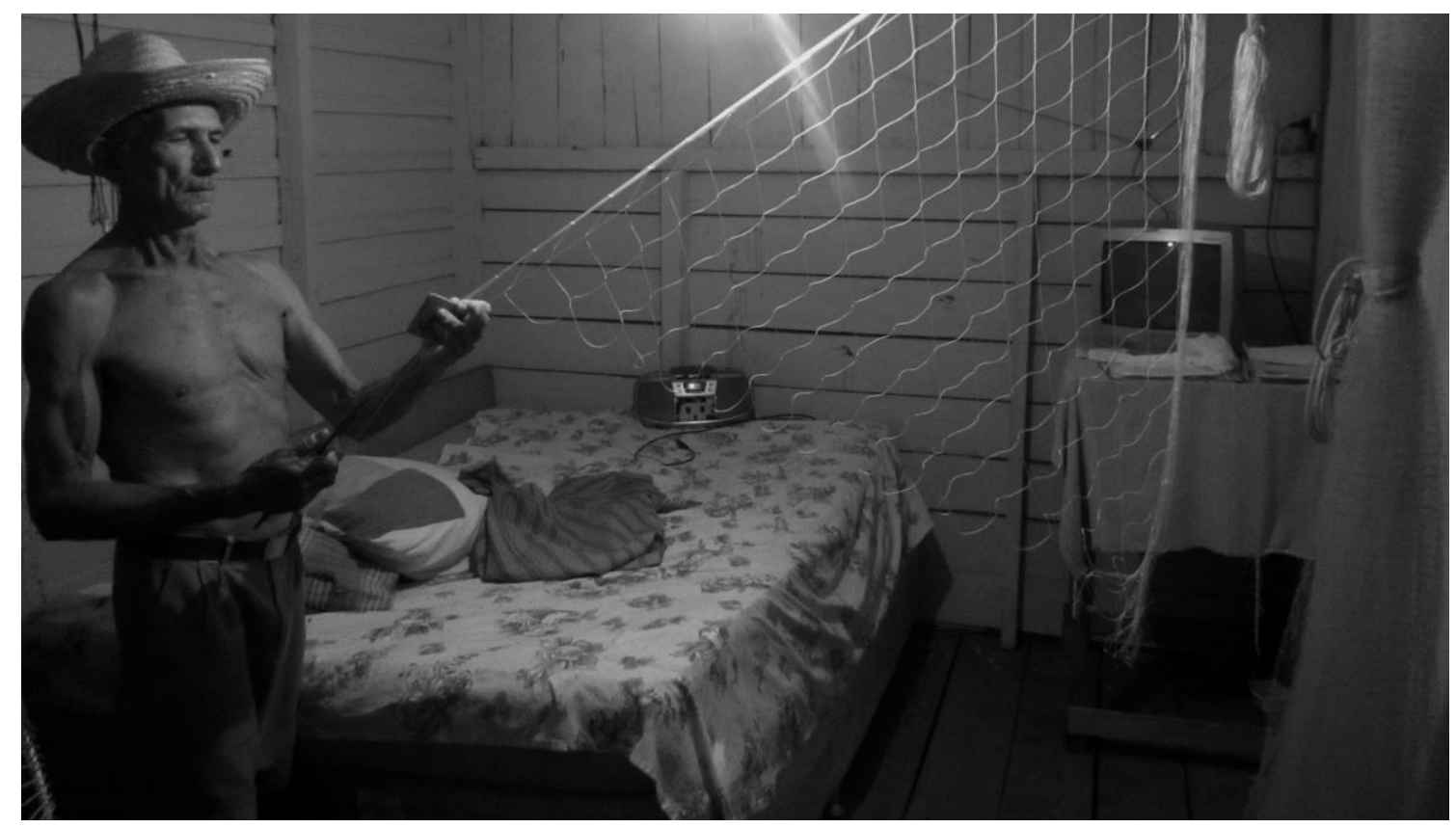

“Essa é a minha malhadeira!” Foto: Igor Erick. 


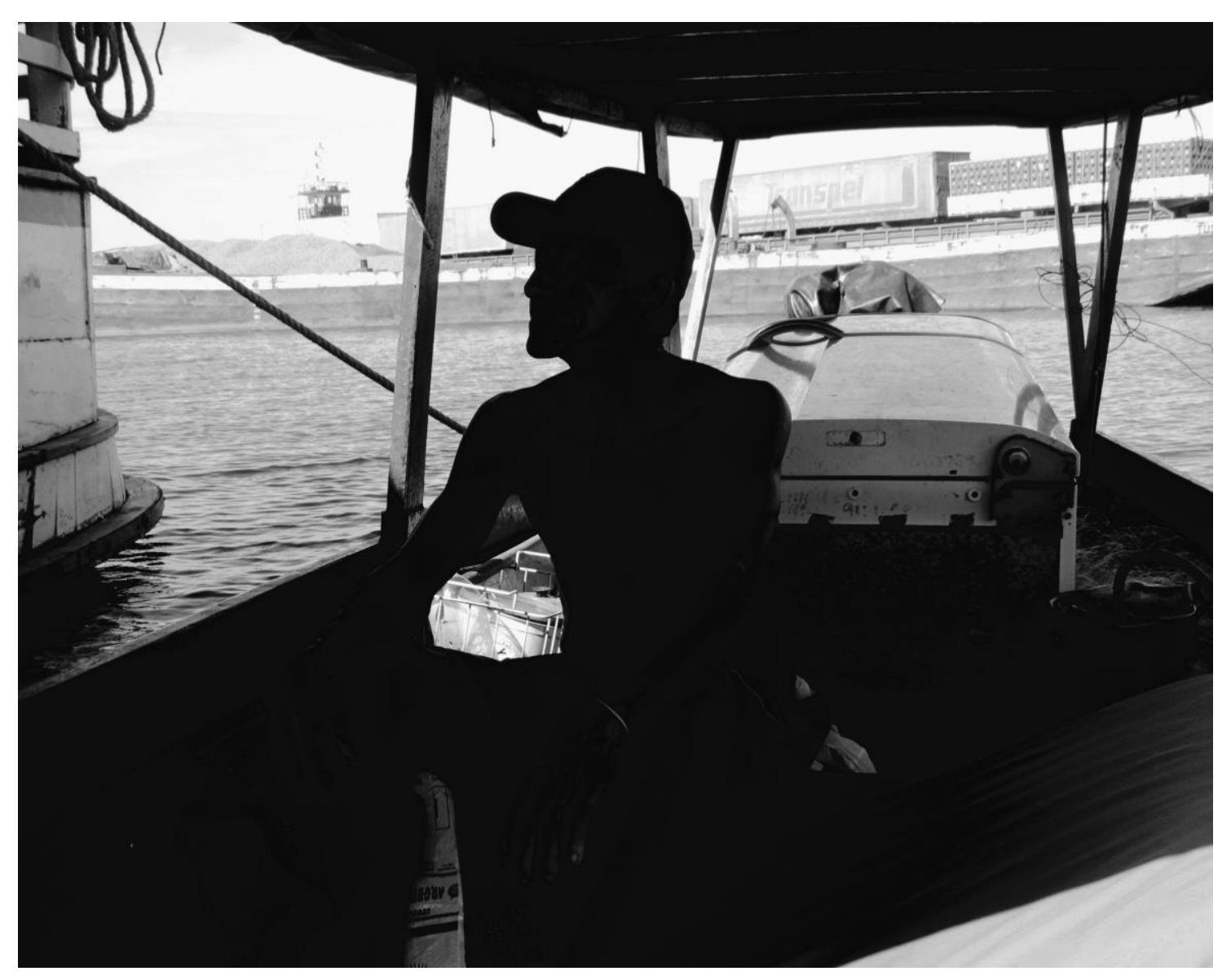

“Essa bajara é a minha segunda casa, mas já estão querendo tomar.” Foto: Igor Erick. 


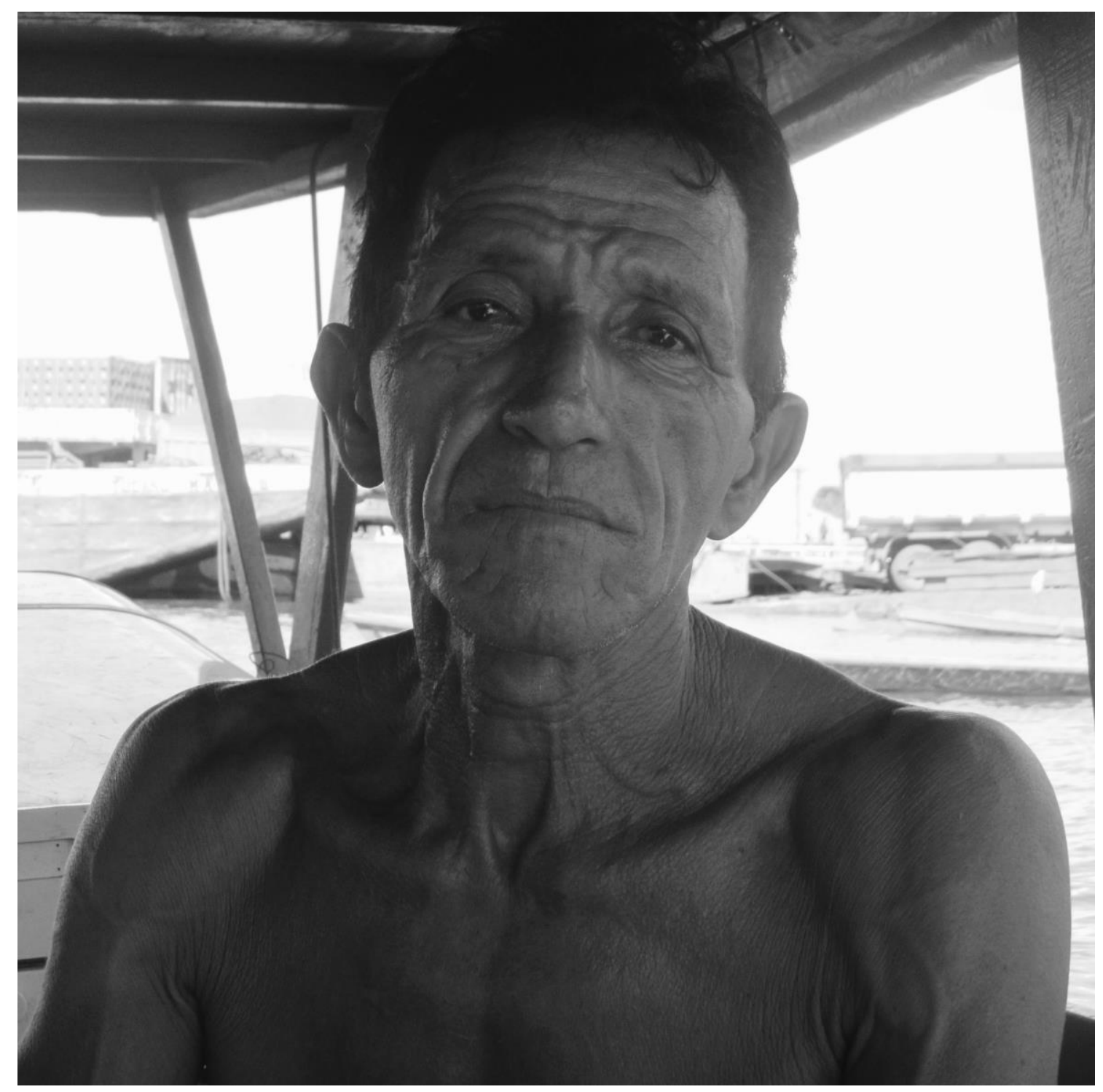

"Vê se eu fiquei bonito...” Foto: Igor Erick. 


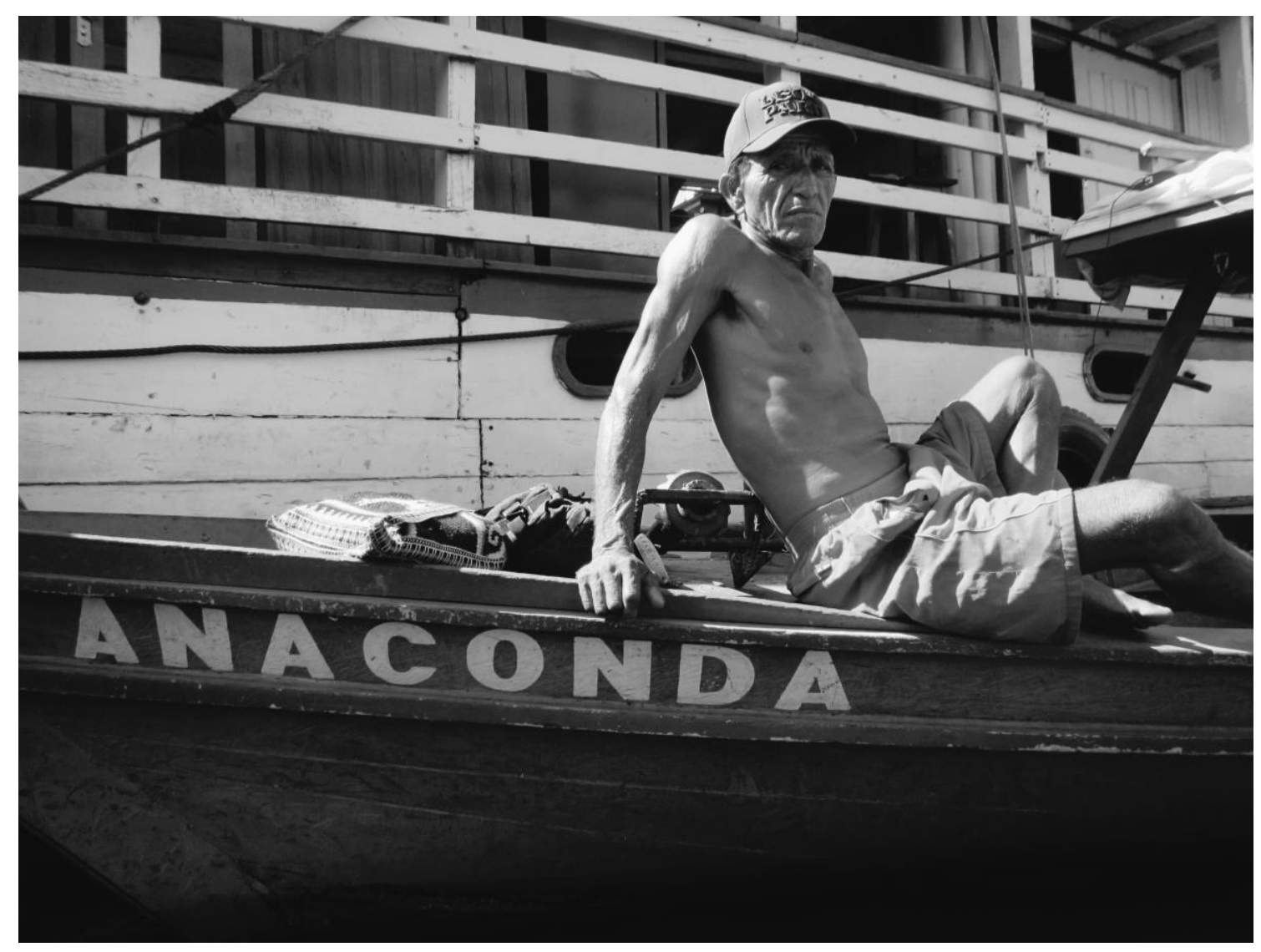

“Essa aqui? Eu matei e coloquei o nome dela aqui!” Foto: Igor Erick. 


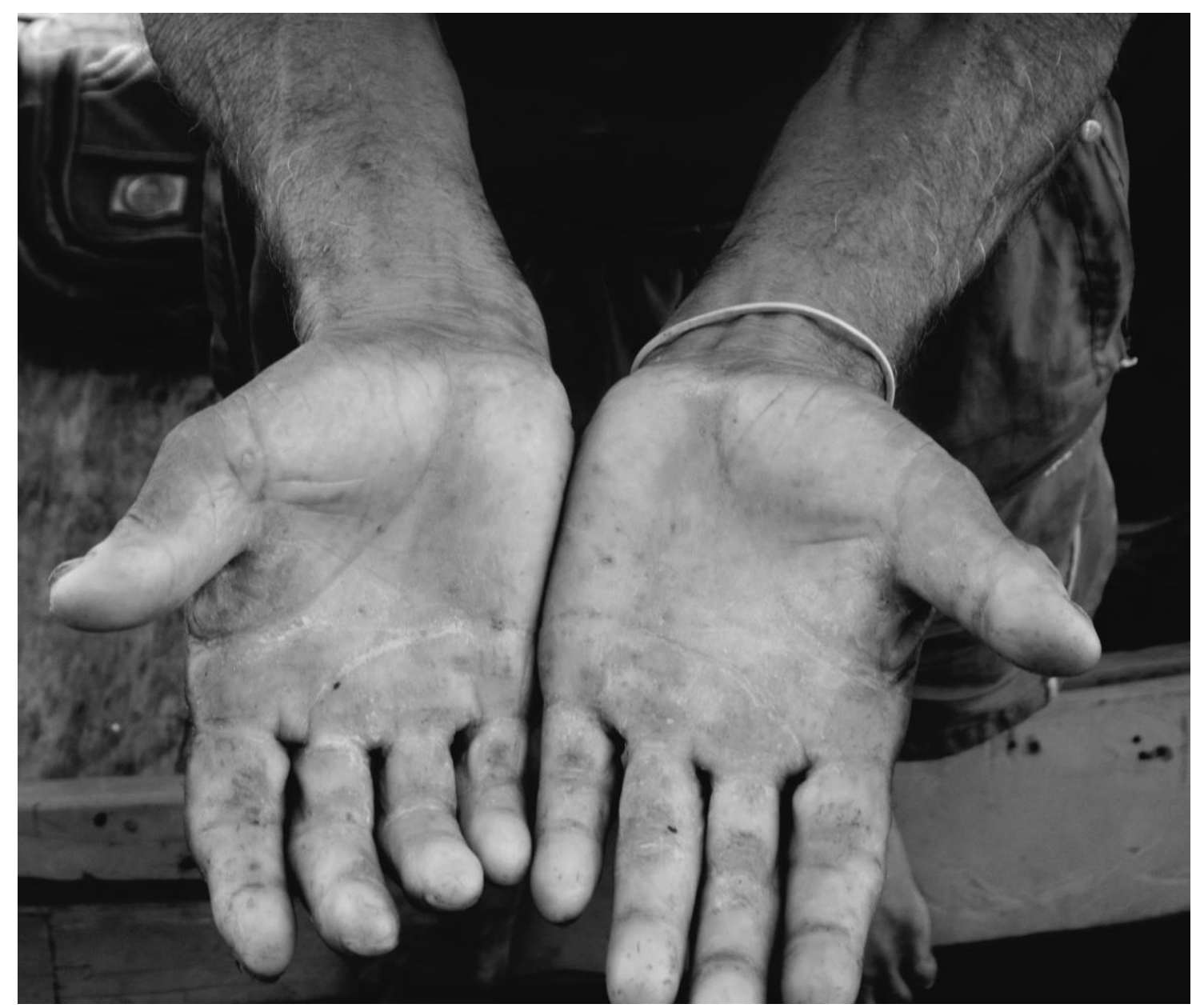

“Espia a minha mão como é que tá, é de tanto entrar nesses igapós...” Foto: Igor Erick. 


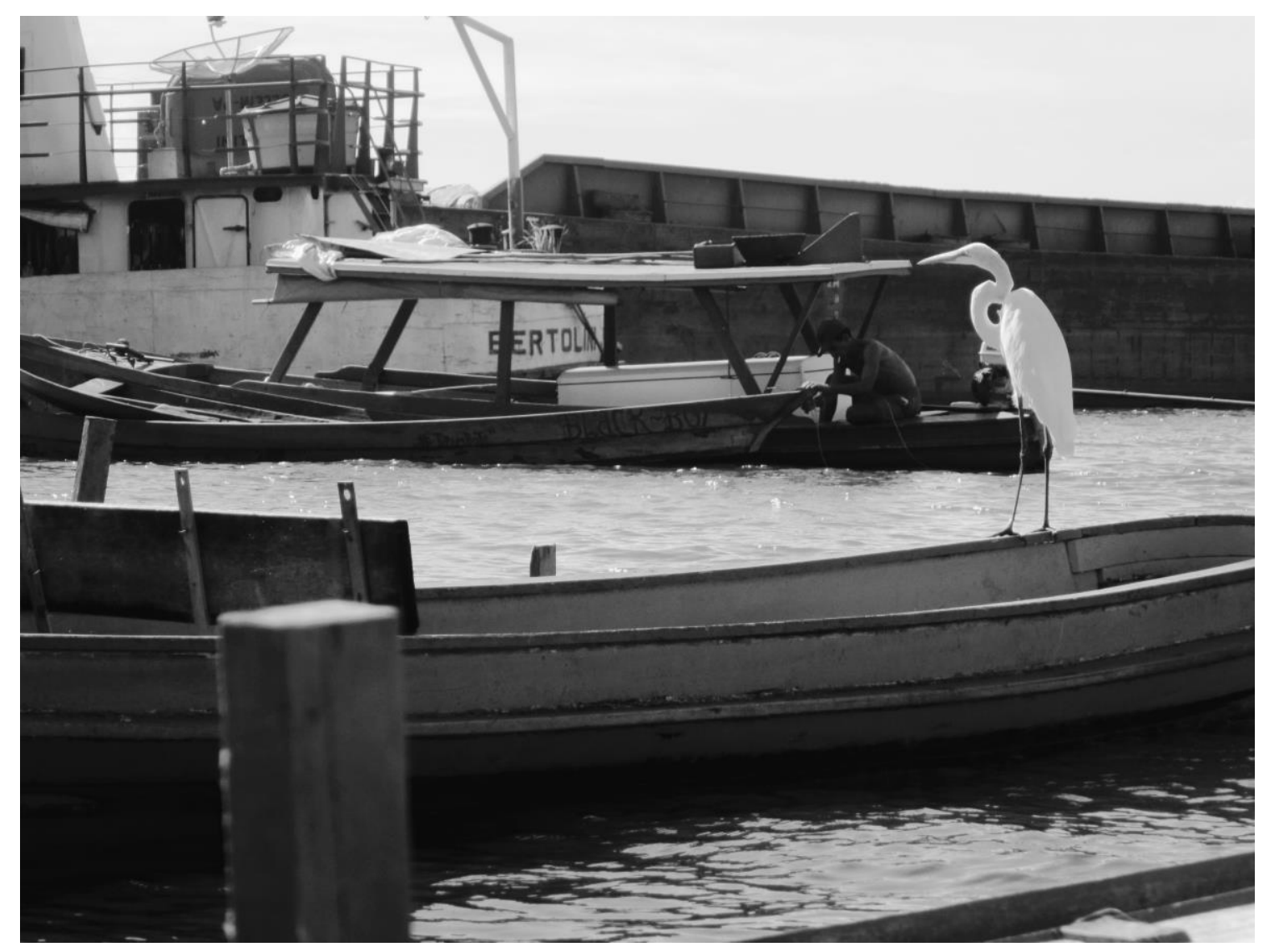

“Já me vu!” Foto: Igor Erick. 


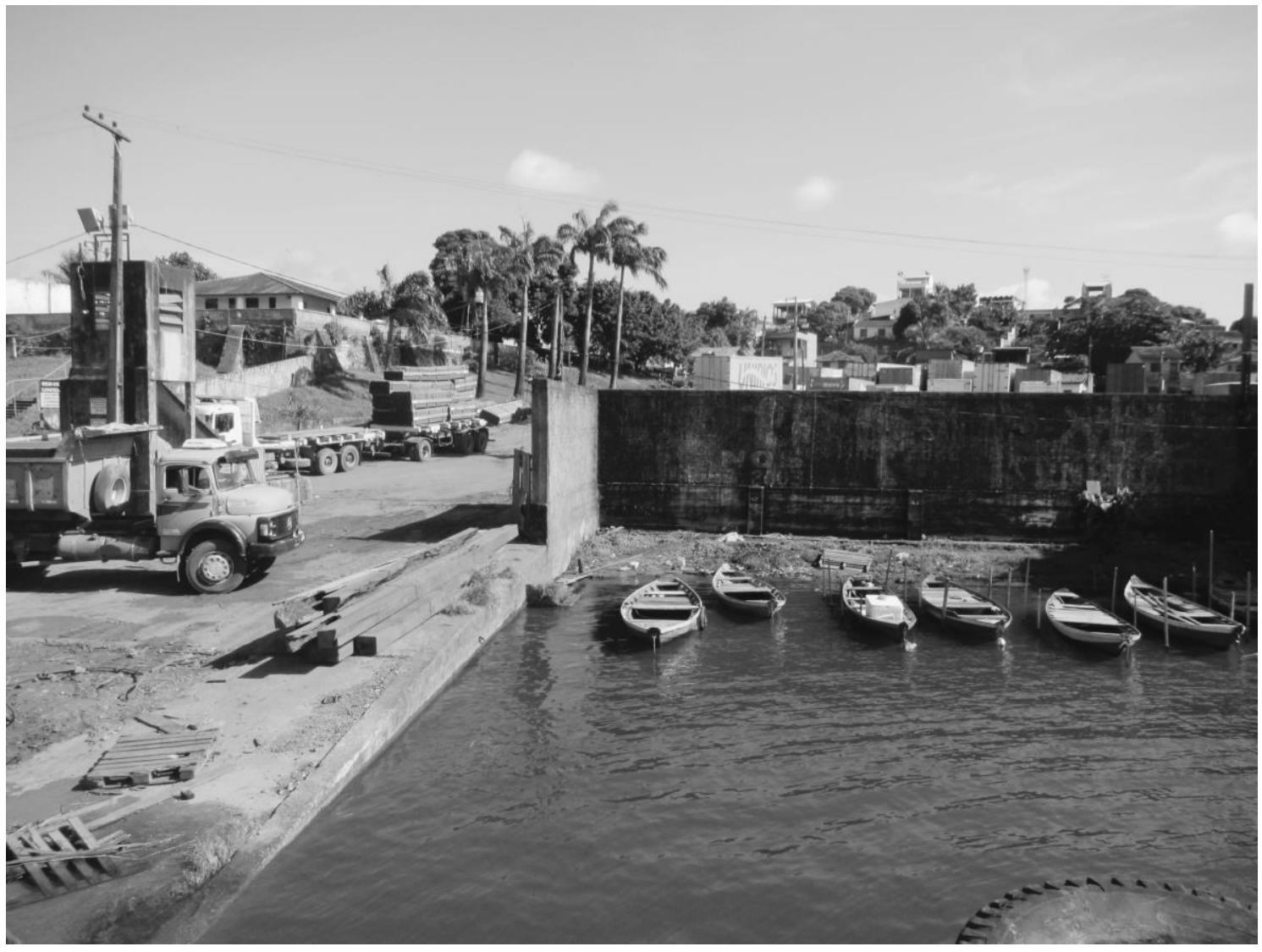

“A desgraça da Unirios [Unirios Rodofluvial e Logística LTDA.]...” Foto: Igor Erick. 


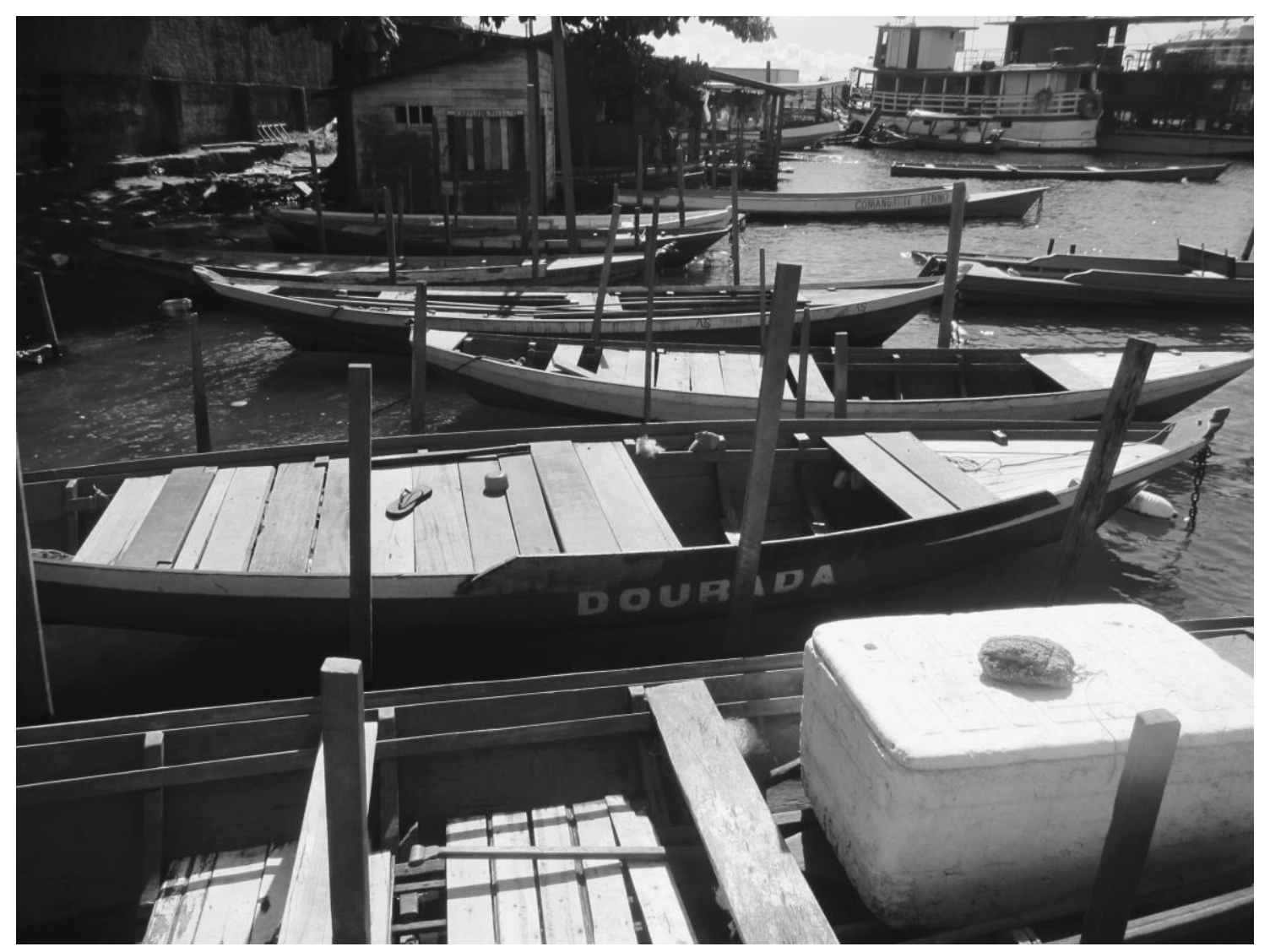

“De um lado é a Unirios e lá na frente onde está o rebocador branco é o estaleiro.” Foto: Igor Erick. 


\section{Referências}

AVIZ, A. A Pesca Artesanal e a Empresa Pesqueira no Município de Óbidos, Pará. Boletim do Museu Paraense Emílio Goeldi. Ciências Humanas, v. 1, n. 2, 2006, p. 77-94.

CASTRO, E.M.R. \& MOURA, E.A.F. Mudanças Sociais e Gestão Ecológica em Questão: a experiência de Mamirauá. Ambiente \& Sociedade, v. 15, n. 2, 2012, p. 66-97.

FAUSTO, C. Os Índios Antes do Brasil. Rio de Janeiro: Zahar, 2000.

FURTADO, L.G. Pescadores do Rio Amazonas. Um Estudo Antropológico da Pesca Ribeirinha numa Área Amazônica. Belém: MPEG, 1993.

FURTADO, L.G., LEITÃO, V. \& MELO, A.F. Povos das Águas: realidades e perspectivas na Amazônia. Belém: MPEG, 1993.

FURTADO, L.G. \& QUARESMA, H.D.A.B. (org.). Gente e Ambiente: o mundo da pesca artesanal. Belém: MPEG, 2002.

MELO, A.F. A Pesca sob o Capital: a tecnologia a serviço da dominação. Belém: EdUFPA, 1985.

NEVES, E.G. Arqueologia da Amazônia. Rio de Janeiro: Zahar, 2006.

PIZARRO, A. Amazônia: as vozes do rio. Belo Horizonte: EdUFMG, 2012.

RODRIGUES, C. I. Caboclos na Amazônia: a identidade na diferença. Novos Cadernos NAEA, v. 0, n. 1, 2006, p. 119-130.

SCHAAN, D.P. Deixando a Terra Natal: as migrações pré-colombianas. In: CANCELA, C.D. \& CHAMBOULEYRON, R. Migrações na Amazônia. Belém: Açaí, 2010, p. 9-26.

WAGLEY, C. Uma Comunidade Amazônica. São Paulo: Ed. Nacional, 1977.

Recebido em: 17/06/2017. Aprovado em: 01/08/2017. 